\title{
Anterior subaxial cervical spine fixation using a plate with single screw per vertebral body: A simple and efficient construct - Clinical series and a cadaver study
}

Prasad S. S. V. Vannemreddy ${ }^{1,2}$, Alan Ogden², D ebi M ukherjee²

${ }^{1}$ Departments of Neurosurgery, NIMS-Hyderabad, India and ${ }^{2}$ LSUHSC-Shreveport, USA

Address for correspondence:

Dr. Prasad Vannemreddy,

Department of Neurosurgery,

LSUHSC, 1501 Kings' Highway,

Shreveport, LA 71103.

E-mail: prasad4458@ hotmail.com

DOI: $10.4103 / 0028-3886.51283$

\begin{abstract}
Abstrad
Objective: To report our experience with a novel construct for traumatic and nontraumatic cervical spine lesions that was validated by biomechanical studies of cadaver cervical spine. Study Design: Consecutive cases of anterior cervical spine fixation performed over six years reviewed for stability offered by a construct comprising of a plate fixed by a single screw to each vertebral body. Setting: A university hospital and a biomechanical lab. Materials and Methods: Data were coded and entered into a statistical worksheet for multivariate analysis. Cadaver spine models applied for biomechanical study of stability. Results: Total of 103 cases reviewed; 86 with single-level disease; traumatic in $66(64 \%)$ cases and degenerative in 33 (32\%) cases, including hard disks, OPLL, and spondylitis (4\% with other causes). Fixation was with diskectomy in 59 and with corpectomy in 40 . A bone graft was utilized for fusion in 87 and a bone-filled titanium spacer in 13. A single screw was placed in each vertebral body with a locking plate (having linear arrangement of holes). This construct remained strong in $95 \%$ of cases at the end of 6-24 months. Five cases failed reQuiring reoperation. Five patients with cervical spinal cord injury (SCI) died. On statistical analysis, construct was stronger with diskectomy compared with corpectomy. Construct used on cadavers confirmed the biomechanical stability in short segment fixation (C5-6). Conclusion: A conservative construct utilizing a single screw per vertebral body and a one-holed plate system appears to be strong enough to afford stability in both traumatic and nontraumatic lesions of subaxial cervical spine, comparable to others.
\end{abstract}

Key words: Anterior fixation, cervical sp ine, construct, subaxial spine

\section{Introduction}

Anterior cervical approach to disk disease of cervical spine was developed by Robinson and Smith and later described by Cloward who also developed several instruments to facilitate the procedure. ${ }^{[1,2]}$ Over past half century the procedure had undergone technical refinements and indications also have increased from the original disk disease to traumatic instability and long segment degenerative diseases. To improve the graft (bone or metal) interface with the vertebral bodies and promote healing by rigid immobilization, anterior cervical plating device has gained widespread favor. Earlier constructs promoted highly rigid plate fixations with a postulation that these plates act as load-bearing devices to promote ideal fusion of interbody grafts with minimal or no graft settling. ${ }^{[3]}$ In multilevel fusions, studies have demonstrated that rigid plate fixation dramatically increases fusion rates. ${ }^{[4-6]}$ However, for single levels, plating may actually decrease 
fusion rates and result in inferior clinical outcomes by increasing stress shielding and hold the graft in excess distraction and preventing appropriate graft settling. ${ }^{[7-9]}$ Even for single-level fusions with and without instrumentation, some authors have reported higher union rates with plating, ${ }^{[6,10]}$ while others performed without plating. ${ }^{[7]}$ The studies in themselves are not free from drawbacks in terms of uniformity in patient population, instrumentation, and graft techniques, thus making it difficult to propose an universal system for any given disease. It is not yet clear from the available literature, if instrumentation is required at all or if there is a need for a heavily rigid construct, which might also predispose patients to adjacent level disease, early. A simpler version of instrumentation that has worked out very well for degenerative as well as traumatic cervical spine lesions in our experience over a decade and when tested in the laboratory had shown stability without serious limitation of mobility.

This study was about early success rate of this simple construct. It is also about the failures that required reoperation in the early postoperative period and not about the fusion rates or the long-term follow-up results.

\section{Materials and Methods}

The material has clinical and cadaver spine biomechanical study data.

\section{Clinical material and methods}

A series of consecutive cervical spine anterior fixation surgeries performed and collected prospectively over eight years, between 1996 and 2004, was reviewed retrospectively. In all these patients, implant with the same principle of fixation was utilized, that is, placing a single screw in each vertebral body with a plate in midline, over the anterior surface of vertebra. Anterior cervical diskectomy and/or corpectomy followed standard operative procedures, performed under general anesthesia and with image-intensifier guidance. All patients received external orthotic support for 4-6 weeks postoperatively. None was immobilized by Halo device after internal fixation of the cervical spine.

Age, gender, number of levels, type of disease (degenerative, trauma, infection), nature of implant (diskectomy followed by graft or corpectomy followed by graft), and construct outcome (revised and stable on follow up) were analyzed.

\section{Statistical analysis}

Data were coded and entered in to multivariate logistic regression analysis (Sigmastat version 3.0.1a., Systat Software Inc.) for identification of variables that influenced failure of the construct in terms of reoperation (following fallout of the implant).

\section{Cadaver cervical spine biomechanical study}

Five cervical spines (C4-C7) were harvested from unembalmed specimens with an average age of 85 years (range 79-91 years). The soft tissue was removed from each spine after harvest and the specimen was frozen until mechanically tested. Prior to the day of testing, each spine was thawed and cortical bone screws were inserted to fuse C4 to C5 and C6 to C7. This method of transarticular fixation assured no movement between the fused levels and did not obstruct movement between the levels in question, C5 and C6. After fusing, the distal portion, C6 and C7, was placed in a mold and encased in automotive body filler (Bondo, Atlanta, GA). Before the potting material had fully cured, a small anterior portion of the filler was removed to allow placement of the plates. After fusion and potting, the specimens were kept in a refrigerator overnight to allow the body filler to cure. The following day, the specimens were removed from the refrigerator to achieve room temperature. A custom- fabricated fixture was then fastened to the C4 superior facet followed by testing in an Instron 8874 biaxial testing frame (Instron Corp, Norwood, MA).

The modes of testing included flexion, extension, and lateral bending in both the right and left directions. Testing in flexion, the distal portion of the specimen was secured in a vice while facing down on the anterior surface. It was then displaced $3 \mathrm{~mm}$ at 0.25 Hertz. Extension testing was conducted at the same displacement and rate with the specimen down on posterior aspect. For both left and right lateral bending, the specimens were held in the same fashion and displaced in the respective left or right directions, $1.5 \mathrm{~mm}$ at 0.25 Hertz. These modes were conducted in the intact, disrupted, and implanted specimens.

\section{Each mode was tested for five cycles}

After completing the intact testing, the intervertebral joint was deconstructed by dividing anterior longitudinal ligament, annulus, disk contents, and the posterior longitudinal ligament with a surgical blade. The four modes of testing were once again conducted. Fusion of C5 and C6 was achieved with the use of a four-holed titanium plate and screws provided by Synthes (Synthes Corp, Paoli, PA). The plate dimensions were approximately $33 \mathrm{~mm} \times 8 \mathrm{~mm}$ and $2.6 \mathrm{~mm}$ in thickness and utilized $2.6 \mathrm{~mm}$ diameter $\times 16 \mathrm{~mm}$ screws in the most proximal and distal holes of the plate. Each specimen was returned to the Instron 8874 and underwent the previous four modes of testing.

\section{Statistical evaluation was performed using t-test}

We certify that all applicable institutional and governmental regulations concerning the ethical use of 
human volunteers were followed during the course of this research.

\section{Results}

\section{Clinical experience}

There were 12 females and 91 males with age range between 12 and 73 years (mean of 39.6; SD 12.9). Singlelevel involvement was seen in $86(83.5 \%)$, two levels in $11(10.6 \%)$, and 3 levels in $6(5.8 \%)$. Traumatic in 66 cases $(64 \%)$ and degenerative in 33 cases (32\%), including hard disks, ossified posterior longitudinal ligament (OPLL), and spondylitic changes. Four cases had destruction by tuberculosis or malignancy (3.8\%). Procedure was an in situ fixation in 3.8\%, diskectomy and implant in 59 $(57.2 \%)$, and corpectomy was required in $40(38.8 \%)$. A bone graft was utilized for fusion in 87 cases $(84.5 \%)$ and a titanium metal spacer filled with bone harvested during corpectomy was placed for fusion in 13 patients $(12.6 \%)$. A single screw was placed in each vertebral body with a locking plate (having linear arrangement of holes). Bicortical purchase was secured using image intensifier. This construct remained strong in $95 \%$ of cases at the end of follow-up ranging between 6 months and 3 years. In five cases $(4.9 \%)$ there was construct failure requiring reoperation; two cases with degenerative spine disease (6\% of degenerative spine) and two with traumatic instability (3\% of trauma) [Figure 1]. Only one out of 59 cases $(1.6 \%)$ of diskectomy with plate fixation had a failed implant requiring reoperation, whereas, 4 out of 40 cases $(10 \%)$ of corpectomy required a revision [Figure 2].

Five patients died in this series, all of them sustained traumatic cervical spinal cord injury $(4.8 \%$ for the total number of patients and $7.5 \%$ for cervical spinal cord injury).

On logistic regression analysis (Sigmastat version 3.0.1a.,

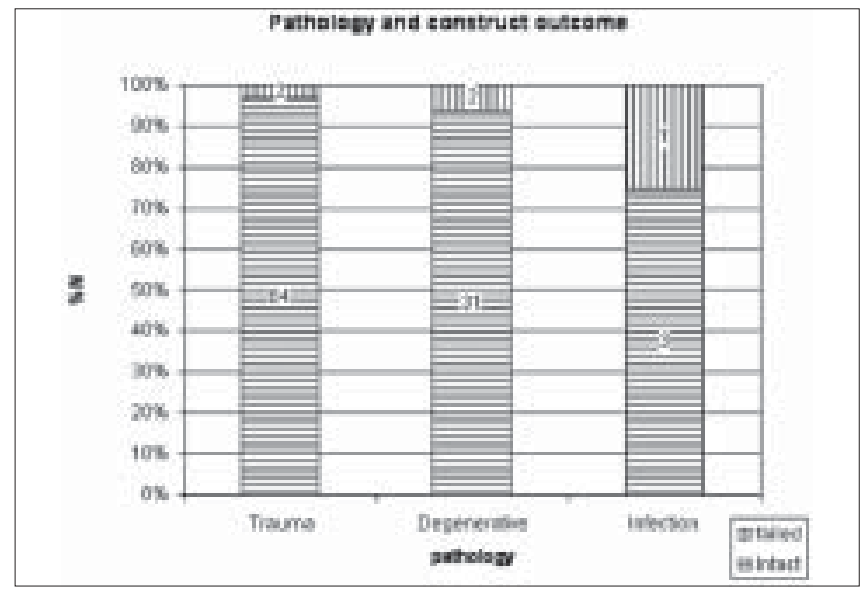

Figure 1: The construct had higher rate of failure in infections and in degenerative spine disease, probably because of the bone quality. The healthy bone of traumatic spine had better
Systat Software Inc.) construct stability was stronger with diskectomy compared to corpectomy $(P<0.03)$.

In some patients, the construct was removed once bony fusion was observed on follow-up radiographs, upon request. The implant extraction was also much simpler and quick compared to the other routinely used implants.

A case each of traumatic instability and degenerative spinal canal stenosis of cervical spine are illustrated with radiographs [Figures 3 and 4], regarding the status of plate fixation in the early postoperative period.

As one would expect with less than 5\% reoperations in the early postoperative period, the statistical significance ( $P$ value of less than 5) could not be assessed.

Results of biomechanics study on cadaver cervical spine Results from the cadaver study showed that the movements of the plated constructs were not statistically different from intact specimens of all four modes of testing at $\mathrm{P}$-values greater than 0.05 . The radiographs show the good profile of the plate with a stable construct [Figures 5a-b].

\section{Inference}

The plated constructs had the same properties as the intact specimens.

The stability of a destabilized specimen is reconstituted using this system [Table 1].

$\begin{aligned} & \text { Table 1: Cadaver study of cervical spine biomechanical } \\
& \text { stability }\end{aligned}$
\begin{tabular}{lccc}
\hline Testing mode & Intact & Plated & $P$-value* \\
\hline Right bending $(\mathrm{N}-\mathrm{m} / \mathrm{mm})$ & $2.12 \pm 0.66$ & $1.97 \pm 0.63$ & 0.72 \\
Left bending $(\mathrm{N}-\mathrm{m} / \mathrm{mm})$ & $2.50 \pm 0.89$ & $2.23 \pm 0.22$ & 0.53 \\
Flexion $(\mathrm{N} / \mathrm{mm})$ & $1.11 \pm 0.44$ & $1.11 \pm 0.38$ & 0.99 \\
Extension $(\mathrm{N} / \mathrm{mm})$ & $1.33 \pm 0.58$ & $1.35 \pm 0.56$ & 0.95 \\
\hline
\end{tabular}

(Stiffness Values); ${ }^{*}$-test values

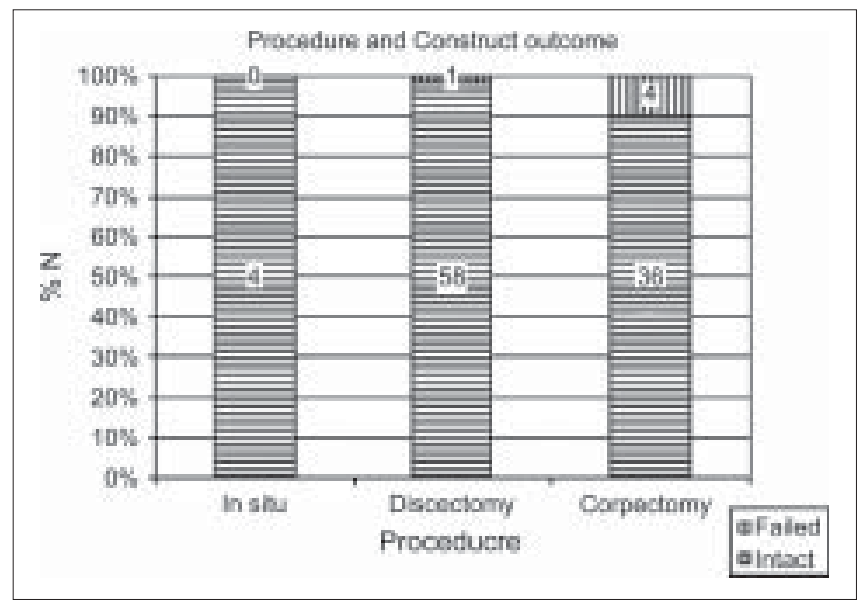

Figure 2: The corpectomy and fixation had worse outcome compared to discectomy and fixation (statistically significant) 


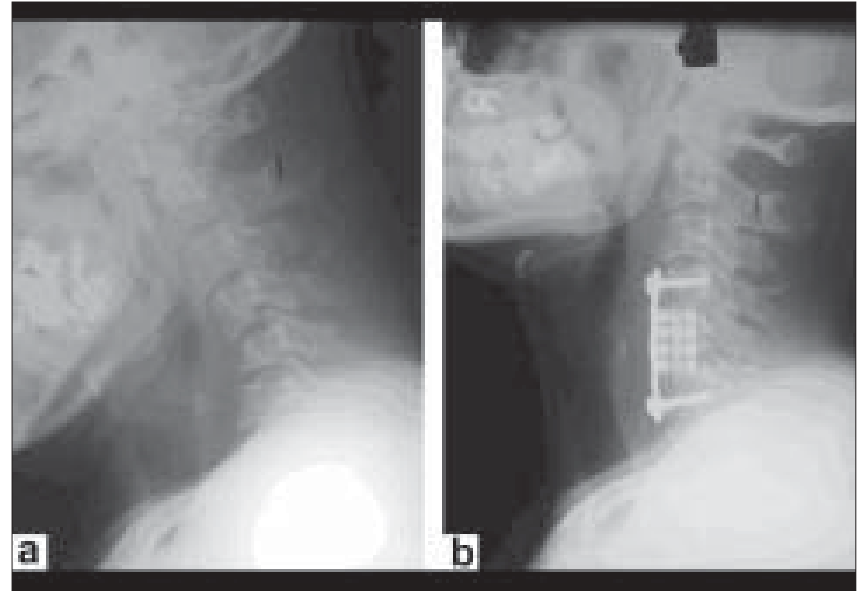

Figure 3: (a) Preoperative radiograph, lateral view of cervical spine following trauma; (b) Traumatic instability with flexion compression injury at C5, lateral view of the postoperative film after fixation with a bone (derived from corpectomy) filled spacer and plate

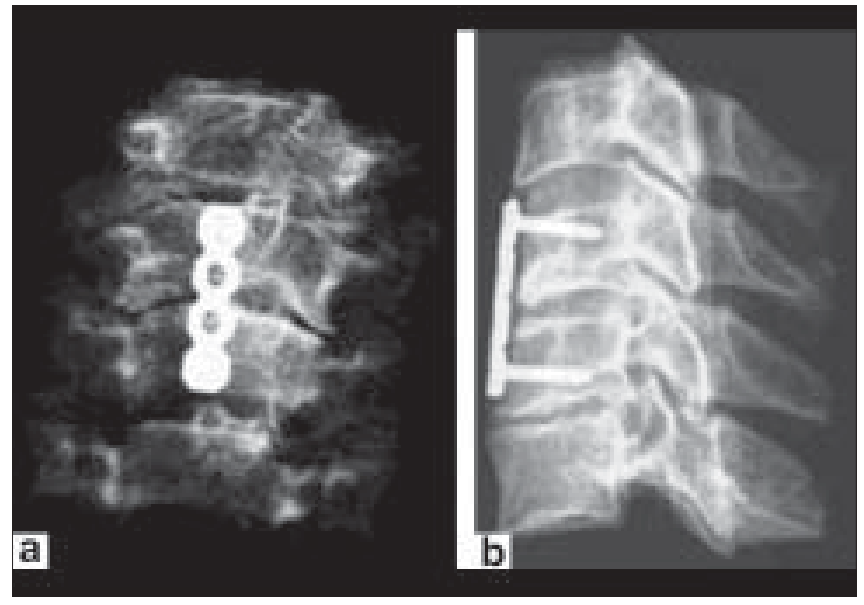

Figures 5: (a-b) Radiographs of the plated cadaver spine (after destabilization) in anterior-posterior and lateral views. The bondo and fixture removed to facilitate radiographs

\section{Discussion}

Initially reported by Robinson and Smith, in 1955, anterior cervical diskectomy and fusion has revolutionized surgical treatment of cervical spine disease. ${ }^{[1]}$ Advent of technological and biomechanical studies boosted our understanding of the spine mobility and instrumentation methodology. It has been all along, promotion of solid bone healing without graft complication, the main objective of anterior cervical spine surgery. However, addressing the need for rigid, semi-rigid, or dynamic fixation methods has been long pending and till date we do not have standard of care method for optimum fixation of cervical spine disease, except of traumatic instability which requires a rigid construct for reasons well documented in the literature. ${ }^{[3-7,11]}$

A bicortical single screw placed in each vertebral

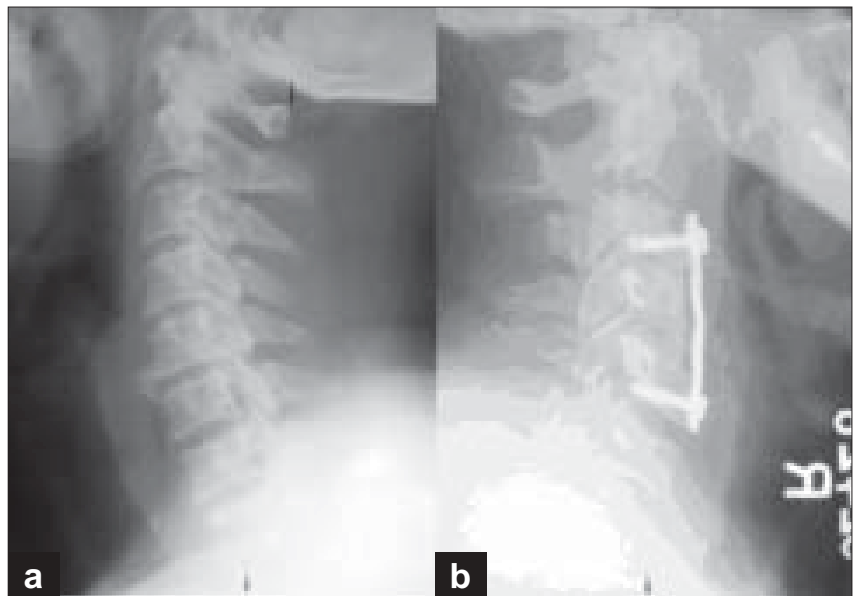

Figure 4: (a-b) Diskectomy and grafting supported by plating had better result while corpectomy had more reoperations. Literature supports this finding of high failures in long-segment fixations, especially with a corpectomy where host and graft interface synchronization is difficult

body secured by a locking plate in the early 90 s had shown encouraging results in many of our patients. The currently, widely available spine instrumentation technology was only evolving during that time. Even with the availability of other fixation systems from Medtronics, Codman, etc., we continued to use the above described (single screw per vertebral body) construct for various reasons. One among them was our experience with these constructs showing low reoperation rate, good bony outcome, less time-consuming procedure, and an implant with less metal occupying less of the prevertebral space. Removal of the implant was also simpler either for reoperation or after the bony fusion. Cost of the implant was also a considerable constraint in some poor patients (each screw would cost more and the plate by the length).

Literature review for reported failures of anterior cervical spine construct failures and the proposed construct reported in the present manuscript have shown encouraging findings [Table 2]. Unfortunately, most of the reports do not demarcate traumatic instability from degenerative disease of cervical spine.

The simple construct was equally stronger and successful. The study was about early failure of the constructs requiring reoperation in the postoperative period and not about the fusion rates and long-term follow-up results.

The biomechanical study on the cadaver cervical spines had revealed interesting findings that might be very useful for us clinically. In the study group, the plated specimens had movement parameters almost similar to those of intact spines. This means that the proposed construct also preserves motion in and around the stabilized segments and results in less stiffness. Our next study aims at rating the neck stiffness experienced 


\begin{tabular}{|c|c|}
\hline Series & Failures \\
\hline Naito et al. 1993 & $\begin{array}{l}7.5 \% \text { (combined trauma and } \\
\text { nontrauma) }\end{array}$ \\
\hline Vaccaro et al. 1998 & $\begin{array}{l}\text { 9\% (two-level degn. spine) } \\
50 \% \text { (3-level degn. spine) }\end{array}$ \\
\hline Geisler et al. 1998 & $6 \%$ (degenerative disease) \\
\hline Barnes et al. 2002 (Atlantis) & $\begin{array}{l}2.6 \% \text { (degenerative disease, } \\
\text { posterior supplementation in } \\
\text { some cases) }\end{array}$ \\
\hline Epstein, 2003 ( $N=42$, corpectomy) & $\begin{array}{l}\text { 9.5\% (one-level corpectomy, } \\
\text { dynamic ABC plate) }\end{array}$ \\
\hline \multicolumn{2}{|l|}{ Single screw construct } \\
\hline $\begin{array}{l}\text { Vannemreddy } 2001(N=79) \\
\text { (IMSOP, Nottwil, Switzerland) }\end{array}$ & $\begin{array}{l}6.3 \% \text { (combined trauma and } \\
\text { nontrauma) } \\
4.6 \% \text { (trauma) } \\
8.3 \% \text { (degenerative disease) }\end{array}$ \\
\hline $\begin{array}{l}\text { Vannemreddy et al. (Present study) } \\
(N=103)\end{array}$ & $\begin{array}{l}3.88 \% \text { (total) } 3 \% \text { (trauma) } \\
6 \% \text { (degenerative) }\end{array}$ \\
\hline \multicolumn{2}{|c|}{$\begin{array}{l}\text { (Part of this clinical work was presented at the Annual meeting of the International } \\
\text { Medical Society of Paraplegia (currently known as International Spinal Cord } \\
\text { Society, ISCoS) in Nottwil, Switzerland, 2001). The above work was presented } \\
\text { at the Annual meeting of the American Association of Neurological Surgeons, } \\
\text { April 2006, San Francisco }\end{array}$} \\
\hline
\end{tabular}

by patients operated by this system in comparison with the other plates fixed by multiple screws.

Undoubtedly, anterior cervical spinal fixation and fusion has come of the age and has become a standard procedure for many lesions of the cervical spine. However, longterm clinical follow-up studies have reported substantial incidence of symptomatic degenerative changes at adjacent segments. In a retrospective radiographic study of 106 patients, Baba et al., reported increased motion at the disk above the fusion segment in approximately $10 \%$ of the patients after an average of 8.5 years. ${ }^{[11]}$ Capen et al., reported degenerative changes above and below an anterior cervical fusion in 36 of 59 patients $(64 \%)$ after an average of 3.5 years of follow up. ${ }^{[12]}$ Gore and Sepic reviewed the cases of 146 patients of anterior cervical fusion in a five-year follow-up study and found $78 \%$ of the patients reported complete relief and 18\% partial relief of neck pain, despite radiographic evidence of spondylitic process at adjacent segments. ${ }^{[13]}$ Further follow up of a subgroup of these patients at an average of 21 years showed that 16 of 48 patients (33\%) who initially reported relief of their symptoms developed recurrent symptoms at an adjacent level. ${ }^{[14]}$ These studies suggest that, although anterior cervical fusion produces excellent relief of symptoms, one-third of these patients may expect recurrences of their pain from degenerative changes at adjacent levels if followed long enough. Anterior fusion inevitably restricts the total range of motion of the cervical spine. Adopting a displacement control scheme assumes patients customarily force their necks to bend through a presurgical range and would involuntarily result in increased demands on the adjacent segments. Schulte et al. performed kinematic studies in cadaveric human cervical spines; they found that after anterior-plated single-level fusions, flexion at the upper and lower adjacent segments decreased by 13.1 and $18.6 \%$ respectively, compared with intact specimens. ${ }^{[15]}$ Similarly, extension decreased by 29.3 and $4.7 \%$, respectively. Patients may compensate the amount of mobility lost to arthrodesis through distant and more mobile joints without overloading segments immediately adjacent to a fusion. The results of another cadaver study revealed that, a single-level anteriorplated fusion causes segmental stiffening of as much as 2.78 times in flexion at the surgical level, its effect on the immediate adjacent segments is significant in axial rotation and lateral bending. ${ }^{[16]}$

Adjacent level disease is over rated. According to Dr. Volker Sonntag, symptomatic adjacent level disk disease is not common and his experience has been under review and pending publication (Personal communication, 2007). Clinically relevant changes may not be a common observation in routine practice following fusion with the rigid constructs at present. However, an implant that matches normal anatomical biomechanics might be an attractive alternative to the currently available metal constructs, especially for singlelevel degenerative disease after diskectomy.

In a recent review of anterior cervical spine surgery for disk disease by Sonntag group, results were found to be equally good for patients who had fusion and fixation compared to those who had no fusion or fixation. ${ }^{[17-22]}$ Furthermore, comparative, prospective clinical trials also failed to find a clinical benefit with anterior cervical diskectomy and fustion (ACDF) ${ }^{[7,8]}$ For a single-level disk disease, however, most surgeons in the United States and Canada still prefer to apply fusion and fixation. This has led to development of biodegradable implants, essentially to prevent graft dislodgement, which also had conflicting results. Brkaric et al.,${ }^{[23]}$ recently reported early failures with the biodegradable plates; three out of six plates failed (one during the procedure and two in the early postoperative period). Almost 100 years after the introduction of surgery for cervical disk disease, we still do not seem to find a consensus or a system that provides an optimal treatment. A best possible solution between a heavy duty metal construct (the currently practiced wide plates with multiple screws) and a fragile one (the biodegradable plates e.g. Mystic, Medtronics) is yet to come out and the simple but effective implant reported in this communication might be useful till that time.

We conclude that a conservative construct utilizing a single screw per vertebral body and a simple one-holed plate system appears to be strong enough to afford stability in both traumatic and nontraumatic lesions of 
subaxial cervical spine, comparable to other currently used constructs. This is time efficient and could be cost effective and had considerably less metal burden on the spine. The biomechanical properties of the construct offer stability while the mobility properties are close to the intact specimen. Our results also suggest that in single-level lesions this construction can be used safely with complete success. The construction had better stability in cases of diskectomy compared with corpectomy cases.

\section{References}

1. Robinson RA, Smith GW. Anterolateral cervical dise removal and interbody fusion for cervical dise syndrome. Bull Johns Hopkins Hosp 1955;96:223.

2. Cloward RB. The anterior approach for removal of ruptured cervical disks. J Neurosurg 1958;15:602-17.

3. Tye GW, Graham RS, Broaddus WC, Young HF. Graft subsidence after instrument-assisted anterior cervical fusion. J Neurosurg (Spine) 2002;97:186-92.

4. Wang JC, McDonough PW, Endow KK, Kevin K, Delamarter RB. Increased fusion rates with cervical plating for two-level anterior cervical discectomy and fusion. Spine 2000;25:41-5.

5. Wang JC, McDonough PW, Kanim LE, Endow KK, Delamarter RB. The Effect of cervical plating on Single-level anterior cervical discectomy and fusion. Spine 2001;26:643-7.

6. Kaiser MG, Haid RW Jr, Subach BR, Barnes B, Rodts GE Jr. Anterior Cervical Plating Enhances Arthrodesis after Discectomy and Fusion with Cortical Allograft. Neurosurgery 2002;50:229-38.

7. Connolly PJ, Esses SI, Kostuik JP. Anterior cervical fusion: Outcome analysis of patients fused with and without anterior cervical plates. J Spinal Disord 1996;9:202-6.

8. Lowery GL, McDonough RF. The Significance of Hardware Failure in Anterior Cervical Plate Fixation: Patients with 2-to 7-Year Follow-up. Spine 1998;23:181-6.

9. Zoëga B, Kärrholm J, Lind B. Springer Plate fixation adds stability to two-level anterior fusion in the cervical spine: A randomized study using radiostereometry. Eur Spine J 1998;7:302-7.

10. Wang JC, McDonough PW, Endow KK, Kanim LE, Delamarter RB. The effect of cervical plating on single-level anterior cervical discectomy and fusion. J Spinal Discord 1999;12:467-71.

11. Baba H, Furusawa N, Imura S, Kawahara N, Tsuchiya H, Tomita K. Late radiographic findings after anterior cervical fusion for spondylotic myeloradiculopathy. Spine 1993;18:2167-73.

12. Capen DA, Garland DE, Waters RL. Surgical stabilization of the cervical spine. A comparative analysis of anterior and posterior spine fusions. Clin Orthop Relat Res 1985;196:229-37.

13. Gore DR, Sepic SB. Anterior cervical fusion for degenerated or protruded dises: A review of one hundred forty-six patients. Spine 1984:9:667-71.

14. Gore DR, Sepic SB. Anterior discectomy and fusion for painful cervical dise disease. A report of 50 patients with an average follow-up of 21 years. Spine 1998;23:2047-51.

15. Schulte K, Clark CR, Goel VK. Kinematies of the cervical spine following discectomy and stabilization. Spine 1989;14:1116-21.

16. Rao RD, Wang M, McGrady LM, Perlewitz TJ, David KS. Does Anterior Plating of the Cervical Spine Predispose to Adjacent Segment Changes? Spine 2005;30:2788-92.

17. Naito M, Kurose S, Oyama M, Sugiyoka Y. Anterior cervical fusion with the Caspar instrumentation system. Int Orthop 1999;17:73-6.

18. Vaccaro AR, Falatyn SP, Scuderi GJ, Eismont FJ, McGuire RA, Singh K, Garfin SR. Early failure of long segment anterior cervical plate fixation. J Spinal Disord 1998;11:410-5.

19. Geisler FH, Caspar W, Pitzen T, Johnson TA. Reoperation in Patients after Anterior Cervical Plate Stabilization in Degenerative Disease. Spine 1998;23:911-20.

20. Barnes B, Haid RW, Rodts GE, Subach BR, Kaiser M. Early results using the Atlantis anterior cervical plate system. Neurosurgery Focus 2000;12:E13.

21. Epstein NE. Anterior cervical dynamic ABC plating with single level corpectomy and fusion in forty-two patients. Spinal Cord $2003 ; 41: 153-8$.

22. Fiez-Erfan I, Klopfenstein JD, Bambakidis NC, Sonntag VK. Surgical management of cervical dise diease: From no fusion to fusion and back again. Clin Neurosurg 2005;52:331-7.

23. Brkaric M, Baker KC, Israel R, Harding T, Montgomery DM, Herkowitz HN. Early failure of bioabsorbable anterior cervical fusion plates. Case report and failure analysis. J Spinal Disord Tech $2007 ; 20: 248-54$

Accepted on 31-03-2009

Source of Support: Nil, Conflict of Interest: None declared. 